\title{
Roadmap for an early gene therapy for cystic fibrosis airway disease
}

\author{
Marianne S. Carlon ${ }^{1}$ (D) | Dragana Vidović ${ }^{1,2}$ | Susan Birket ${ }^{3}$
}

\author{
${ }^{1}$ Molecular Virology and Gene Therapy, \\ Department of Pharmaceutical and \\ Pharmacological Sciences, KU Leuven, \\ Flanders, Belgium \\ ${ }^{2}$ Current affiliation: Cellular Protein \\ Chemistry, Faculty of Science, Utrecht \\ University, The Netherlands \\ ${ }^{3}$ Department of Medicine, University of \\ Alabama at Birmingham, Birmingham, AL, USA \\ Correspondence \\ Marianne Carlon, Molecular Virology and \\ Gene Therapy, Department of Pharmaceutical \\ and Pharmacological Sciences, KU Leuven, \\ Flanders, Belgium. \\ Email: marianne.carlon@med.kuleuven.be \\ Funding information \\ "Fund Alphonse and Jean Forton", King Bau- \\ douin Foundation, Belgium, Grant/Award \\ Number: 3 M140231
}

\begin{abstract}
Gene therapy provides a mutation-independent approach to treat or even cure CF airway disease. To develop a clinical candidate for CF gene therapy, a thorough examination of preclinical efficacy in relevant cell and animal models is a prerequisite. For a long time, the CF field was struggling with a lack of appropriate animal models for CF airway pathology. Since 2008, many different and complementary animal models have been generated that develop hallmarks of CF airway disease, including the CF pig, ferret, and rat. With this, a new era has arisen that allows investigating the efficacy of gene therapy beyond molecular and electrophysiological end-points. Successful gene therapy most likely requires an appropriate time window. CF lung pathology progresses with age and therefore an early treatment would be beneficial to prevent irreversible damage. In that regard, newborn screening programs and prenatal diagnosis already provide a basis to facilitate future preventive gene-based treatment. If successful, gene therapy for CF airway disease would markedly reduce the treatment burden and improve life quality and life expectancy of CF patients.
\end{abstract}

\section{1 | INTRODUCTION}

During the last decades, medical knowledge moved forward significantly, providing better care and nursing. We live longer than ever before, still most remedies do not tackle the underlying disease cause, but merely treat symptoms. Gene therapy holds promise to cure a wide range of genetic and acquired disorders and has become a valuable treatment for genetic disorders, such as adenosine deaminase deficiency, $\mathrm{X}$-linked severe combined immunodeficiency, congenital blindness, hemophilia B, spinal muscular atrophy, and lipoprotein lipase deficiency. ${ }^{1-6}$ However, the unparalleled clinical potential of gene therapy is yet to be proven for cystic fibrosis (CF).

$\mathrm{CF}$ is a chronic autosomal recessive genetic disorder caused by mutations in the cystic fibrosis transmembrane conductance regulator (CFTR), resulting in multi-organ pathology. Lung disease however is the major cause of mortality. Despite better symptomatic care, the median age at death remains early thirties. ${ }^{7}$ The pathophysiology of CF relates to mutations in CFTR (>2000, www.genet.sickkids.on.ca), a chloride/ bicarbonate channel. This channel also regulates other epithelial ion transporters, such as non-CFTR chloride channels and the epithelial sodium channel, ENaC. ${ }^{8}$ CFTR directly regulates the airway surface liquid (ASL) height through chloride and water transport but is also thought to play an important role in the release and unfolding of mucus granules from the submucosal glands and surface epithelium through bicarbonate secretion. ${ }^{9}$ Both these processes are disturbed in CF and lead to impeded ciliary activity, mucostasis, and viscous secretions. Additionally, reduced ASL $\mathrm{pH}$ caused by defective bicarbonate secretion leads to abnormal innate immunity of the airways, as seen in studies in neonatal CF pigs and ferrets. ${ }^{10,11}$ Combined, these defects result in the inability of CF airways to efficiently eradicate pathogens, contributing to recurrent and chronic infection, excessive inflammation, and lung damage.

Since the discovery of the CFTR gene in 1989, ${ }^{12-14} 27$ clinical trials have been conducted with viral vectors or non-viral vehicles (reviewed in Sondhi et $\mathrm{al}^{15}$ and Alton et $\mathrm{al}^{16}$ ). The safety and tolerability of different vectors have been proven, but none have led to a persistent clinical benefit. The most recent study by Alton et al demonstrated that liposome delivery of CFTR cDNA stabilized lung function (forced expiratory volume in 1 second) in treated patients, whereas a further decline was observed in the placebo group. ${ }^{17}$ Although the benefit was modest, these results fuel further research on CF gene therapy. This review therefore sets out a roadmap for successful clinical gene therapy. We discuss the progress made and phrase the remaining 
questions to be answered in the broad portfolio of available cell and animal models of CF lung disease.

\section{I FROM GENE ADDITION TO GENE EDITING-EFFICIENCY OF GENE DELIVERY MATTERS}

Gene therapy in its broadest context means transfer of therapeutic DNA or RNA into a target tissue to correct the function of a protein that, if dysfunctional, leads to a hereditary or acquired disorder. The most straightforward procedure is gene addition therapy, a strategy used since the early nineties for many monogenetic disorders including CF. ${ }^{15}$ The aim is to introduce the correct genetic information of a mutated gene by introducing the coding sequence of this gene and delivering it to affected organ(s). Gene correction by gene editing on the other hand refers to the process of correcting the endogenous mutated gene in its genomic location using "nuclear scissors", eg, Cas9, Zinc-finger, or TALE nucleases. ${ }^{18,19}$ Additional delivery of a repair template allows the original DNA sequence of the affected gene to be restored by homology directed repair. The latter is exemplified by correction of the most common CF-causing mutation (F508del) using CRISPR/Cas9 in patient-derived intestinal organoids. $^{20}$ The major obstacles for transferring gen(om)e editing strategies to the clinic are insufficient fidelity, ${ }^{21,22}$ low efficacy in vivo, and existing challenges for stem cell engraftment after transplantation. ${ }^{23,24}$ Nevertheless, it is a highly promising gene therapeutic strategy, and future work will undoubtedly extend the current limits of this approach.

Efficient correction of genetic disorders depends on the efficacy of gene delivery, which remains the major hurdle for clinical success. Nevertheless, considerable progress has been made in viral and nonviral vectors since recombinant DNA technology hit the stage in the 1970 s. $^{25-28}$ Non-viral vectors include cationic liposomes, which fuse to the plasma membrane of the cell, ${ }^{29}$ or poly(lactic-co-glycolic) acid nanoparticles which can be modified with targeting ligands or cell penetrating peptides for enhanced uptake. ${ }^{30}$ Advantages include incorporation of large transgenes and low immunogenicity, allowing repeated administration. Poor transduction efficiency is the main limitation as transport from cytoplasm to nucleus is rate limiting. ${ }^{26}$ By contrast, viral vectors have an inherent mechanism to efficiently enter the host cell and nucleus. Monthly administrations of liposome-CFTR cDNA complexes to CF patients' airways in a phase Ilb trial showed that gene delivery was well tolerated, but the efficacy modest, ${ }^{17}$ underscoring the need for more potent gene therapeutic strategies. Adenoviral vectors (AdV) were the first vectors tested clinically for CF in the early 1990s. ${ }^{31,32}$ CFTR expression was however transient, and repeated doses did not increase the clinical benefit due to high immunogenicity. ${ }^{33,34}$ A new generation of helper-dependent (HD) AdV has been developed, devoid of viral genes. ${ }^{35}$ Current preclinical work focuses on the longevity of transgene expression in airways, one of the major obstacles in the past. ${ }^{36}$

In parallel, recombinant adeno-associated viral vectors ( $\mathrm{rAAV}$ ) for CF gene therapy were extensively tested clinically. rAAV have low immunogenicity, (mainly) are non-integrating, and devoid of viral

\section{What is already known about this topic?}

- 27 gene therapy clinical trials for cystic fibrosis (CF) have demonstrated safety and tolerability, but none a persistent clinical benefit.

- Progress in vector technology and animal models with human CF-like lung disease hold promise to develop and reliably test an effective gene therapy for CF.

- Preclinical studies on fetal gene therapy point out specific advantages compared with postnatal gene therapy, but further comparative studies are needed to substantiate these findings.

\section{What does this study add?}

- This review sets out a roadmap for successful gene therapy in the clinic. We discuss the progress made and list the remaining questions to be answered in cell and animal models of CF lung disease.

- To prevent irreversible lung damage early gene therapy is key. The advantages of starting gene therapy in the neonatal or even fetal period are discussed and are weighted against the inherent risk for complications.

genes. ${ }^{37}$ Their packaging capacity of approximately $5 \mathrm{~kb}$ potentially limits its use for larger genes, such as CFTR (4.4 kb). In 2012, the EMA approved the first rAAV gene therapy (Glybera, UniQure) for lipoprotein lipase deficiency (www.ema.europa.eu). The first and best studied serotype (rAAV2/2) was used in initial trials to deliver fulllength CFTR cDNA to the respiratory tract under the control of a weak inverted terminal repeat (ITR) promoter. ${ }^{38-42}$ Whereas an improvement in lung function was observed in a first trial, ${ }^{40}$ there was no clinical benefit in a larger follow-up study. ${ }^{41}$ In retrospect, absence of receptors for this serotype at the apical side of the airway epithelium, the weak promoter or effective barriers in CF patients' lungs might have contributed to inefficient gene transfer. ${ }^{43}$ Nevertheless, these studies confirmed the favorable safety profile of rAAV with only a few adverse effects potentially related to vector treatment. Current research focuses on improving transduction efficacy by using alternative, airway-tropic rAAV serotypes ${ }^{44-47}$ and promoters ${ }^{47-49}$ and/or optimizing the expression cassette to accommodate a CFTR minigene. ${ }^{45,50-52}$

Lentiviral vectors (LV) have been studied only preclinically. ${ }^{53-55} \mathrm{LV}$ have shown long-term gene expression in mouse models. ${ }^{54,56}$ It is yet to be shown whether sustained gene expression arises from vector integration into stem cells, or transduction of long-living terminally differentiated epithelial cells. ${ }^{57}$ A complete overview of all preclinical and clinical progress on CF gene therapy is given by Sondhi and colleagues. $^{15}$ 


\section{3 | WHAT HAVE CF MOUSE MODELS TAUGHT US ABOUT GENE THERAPY?}

CF mice were the only available animal models to study gene delivery to the airways until the first $\mathrm{CFTR}^{-/-}$pig was produced in $2008 .^{58,59}$ An overview of all CF mice and their phenotypic similarities and discrepancies compared with humans is given in Wilke et $\mathrm{al}^{60}$ and Conese et $a^{61}$ Although CF mice do not spontaneously develop lung disease, they mimic the abnormalities in ion transport in the upper airways (nose). Also, cell composition is similar to human airways. ${ }^{62}$ Therefore, the mouse nose can be used as a read-out for CFTR function. A protocol for nasal potential differences (NPD), a CFTR biomarker in humans, has been adapted for use in CF mice. ${ }^{63,64} \mathrm{We}$ demonstrated rescue of CFTR activity by NPD in the CF mouse nose after rAAV2/5 delivery of a shortened CFTR (CFTR $\triangle R^{49}$ ), lacking a portion of the regulatory domain, which retains regulated channel activity. ${ }^{45}$ Also, other vectors, such as LVs or a gene editing nanoparticle formulation, could partially restore CFTR function in CF mice as measured by improvements in NPD. ${ }^{65,66}$ Furthermore, mouse models have been instrumental in addressing generic outcomes of gene therapy, ie, transduction efficiency, cell-specific tropism, immune responses to vector and transgene, and longevity of gene expression (reviewed in Mingozzi and $\mathrm{High}^{67}$ ). In non-CF mouse airways, we have shown sustained reporter expression till 15 months after rAAV2/5 delivery, a substantial proportion of the lifespan of a laboratory mouse. ${ }^{46}$ Nevertheless, this question remains to be re-investigated in an animal model spontaneously developing lung disease, such as the $\beta$-ENaC overexpressing mouse or the CF rat, ferret, and pig. ${ }^{59,68-70}$ This because chronic inflammation leads to enhanced turnover of respiratory epithelium and transduction efficacy of many vectors is hampered by their inability to penetrate excessive mucus combined with infiltrating immune cells. ${ }^{71,72}$ On the other hand, misfolded mutant CFTR, eg, F508del, leads to endoplasmic reticulum stress, which renders the cell less equipped to block viral vector trafficking. As such, transduction of F508del overexpressing cells with rAAV2-eGFP was significantly enhanced compared with wild type (WT)-CFTR cells. ${ }^{73}$ Similarly, proteasome inhibitors co-delivered with rAAV in mice, dogs, and ferrets led to enhanced transduction. ${ }^{74,75}$ They are postulated to enhance transduction by preventing degradation of rAAV capsids, although their exact mechanism remains unknown. ${ }^{76}$ These studies point out the complexity of predicting in vivo efficacy as many factors influence this process, including inflamed CF airways and subcellular stress caused by specific CFTR mutations or infections.

\section{I A NEW ERA OF CF ANIMAL MODELS AND READ-OUTS TO STUDY THE HALLMARKS OF CF AIRWAY DISEASE}

The CF rat, ferret, and pig represent human physiology and CF pathology more faithfully compared with CF mice and hence are a great

TABLE 1 Overview of clinically most relevant lung disease parameters of available CF animal models

\begin{tabular}{|c|c|c|c|c|}
\hline & Mouse $^{a, b}$ & Rat & Ferret & Pig \\
\hline CF-like bioelectric properties & $Y_{e s}^{60,62 c}$ & $\mathrm{Yes}^{77}$ & Yes $^{70,83,128}$ & Yes $^{79,84,85}$ \\
\hline Altered $\mathrm{pH}$ of $\mathrm{ASL}$ & $\mathrm{No}^{86}$ & $Y_{e s}{ }^{87}$ & $Y_{e s}{ }^{11}$ & Yes $^{10,79}$ \\
\hline Changes in mucus composition (eg, increase in mucus solids) & NR & NR & NR & Yes $^{89}$ \\
\hline Defective mucociliary clearance & $\mathrm{No}^{60,90}$ & $Y_{e s}^{87}$ & Yes $^{11,128}$ & $\mathrm{Yes}^{80,82,108}$ \\
\hline Mucus accumulation/obstruction & $\mathrm{No}^{60}$ & NR & Yes $^{105}$ & $Y_{e s}^{80,113}$ \\
\hline Defective innate immunity (eg, reduced activity of antimicrobials, immune cell defects) & $Y_{e s}^{60,93,94}$ & NR & $Y^{11}$ & Yes $^{10,79}$ \\
\hline Spontaneous infection & $\mathrm{No}^{60}$ & NR & $Y_{e s}^{11,128}$ & Yes $^{10,95,109}$ \\
\hline Anatomical defects of the airways (eg, tracheomalacia, sinus hypoplasia) & Yes $^{96}$ & $Y_{e s}{ }^{77}$ & NR & $Y_{e s}{ }^{78,95,97,98}$ \\
\hline Human-relevant CFTR mutations & Yes $^{60,62}$ & NR & NR & $Y_{e s}^{58,99}$ \\
\hline In utero presence of lung abnormalities (eg, tracheomalacia, abnormal lung development ${ }^{f}$ ) & NR & NR & NR & NR \\
\hline
\end{tabular}

Legend: This overview covers all models related to the Cftr gene, including knock-out and knock-in models where a specific mutation is introduced into the endogenous $\mathrm{Cft}$ gene of the model species used.

Abbreviations: ASL, airway surface liquid; NR, not reported; PCL, periciliary liquid height.

aThe $\beta$-ENaC overexpressing mouse presents many features of CF airway disease, including a significant reduction in PCL height and mucociliary clearance, mucus retention and plugging, and finally asphyxia and death. ${ }^{68}$

${ }^{b}$ For a full overview of all lung-related phenotypes of the many different CF mouse models available, see reviews. ${ }^{60,100}$

'Loss of cAMP-induced CFTR chloride currents in nasal epithelium of $\mathrm{Cftr}^{-1-}$ mice is genetic background dependent ${ }^{60}$; in trachea and bronchi, this loss is compensated by calcium activated chloride channels (CaCC, TMEM16A). ${ }^{62,101,102}$ Mouse CFTR in nasal epithelium is expressed principally in brush cells, not in ciliated cells. ${ }^{60}$

${ }^{\mathrm{d}}$ Submucosal glands only present in nose and proximal trachea.

${ }^{\mathrm{e}}$ Mouse serous cells lack cAMP-mediated $\mathrm{Ca}^{2+}$ signaling to activate basolateral membrane $\mathrm{K}^{+}$conductance, resulting in weak cAMP-driven serous cell fluid secretion compared with human glands. ${ }^{103}$

${ }^{f}$ CFTR has been implicated in normal lung organogenesis in utero from studies in sheep and humans, ${ }^{104,105}$ but abnormal lung development in subjects with CF remains to be demonstrated. 
advance in modeling this disease. ${ }^{58,59,70,77,78}$ An important feature of these models is the presence of submucosal glands (SMGs) throughout the proximal airways. CF airway pathology is largely attributed to defects in the SMGs as CFTR dysfunction is associated with abnormal mucus secretion and defective innate immunity. ${ }^{11,79-82}$ SMGs are therefore proposed as one of the targets for gene therapy. An overview of the main hallmarks of each model related to airway disease, including the CF mouse models, is presented in Table 1.

CF animal models that spontaneously develop lung disease allow investigating the efficacy of gene therapy beyond molecular and electrophysiological end-points. In 2016, 2 gene therapy studies conducted in the newborn gut-corrected $\mathrm{CFTR}^{-/-}$pig reported that early disease manifestations of CF could be treated with a gp64pseudotyped LV or rAAV2H22. These are the first studies reporting on the ability of gene therapy to improve clinically relevant lung disease features in the neonatal period, such as increased bacterial killing and ASL pH. ${ }^{55,106}$ Read-outs on key features of progressing lung disease are emerging, including particle tracking ${ }^{80}$ or micro-optical coherence tomography ${ }^{77,107}$ for identifying changes in mucociliary clearance. Computed tomography (CT) or $\mu \mathrm{CT}$ can reveal structural lung damage (bronchiectasis, airway wall thickening, bronchial obstruction, collapse of lung segments) ${ }^{108-111}$ as well as abnormalities in lung function (airflow obstruction, air trapping) with inspiratory versus expiratory $\mathrm{CT} .{ }^{112}$ Pulmonary function tests inform on vital capacity, resistance, and compliance of the respiratory system. Forced expiratory volumes (FEV) can be obtained in animals, but is not yet routinely used. ${ }^{113,114}$ The human equivalent of this, FEV in 1 second $\left(\mathrm{FEV}_{1}\right)$, is the primary end-point in most clinical trials. These read-outs will allow detailed evaluation of novel gene therapies: how and to what extent do individual factors improve lung disease phenotypes.

\section{5 | AN EARLY INTERVENTION TO PREVENT PROGRESSIVE LUNG DISEASE}

There is a growing consensus that treating CF patients early is crucial to prevent irreversible lung damage. Evidence is given in other disease areas, for instance, in congenital blindness trials where $\mathrm{rAAV} 2 / 2$ gene therapy resulted in the greatest increase in eye sight in youngest patients. ${ }^{1}$ For an inherited lysosomal storage disorder, disease progress could be prevented in pre-symptomatic patients, further supporting the concept of an early treatment. ${ }^{115}$ Initiating treatment early in children with CF depends on a timely diagnosis. Traditionally, diagnosis relied on recognition of characteristic clinical symptoms, but in many countries, newborn screening is now a common practice. ${ }^{116}$ Also, many populations are screened for maternal carrier status. Via prenatal ultrasound screening, meconium ileus, peritonitis, and bowel obstruction can be identified, caused by CFTR dysfunction in the gastro-intestinal tract. ${ }^{116}$ Starting symptomatic treatment just after diagnosis via positive newborn screening has shown to improve outcomes compared with treatment initiation after diagnosis via symptoms. ${ }^{117}$ For therapies targeting the underlying CFTR defect, the anticipated impact of preventive therapy is even bigger. Due to better symptomatic care, classical lung function parameters such as $\mathrm{FEV}_{1}$ remain in the normal range throughout childhood in many patients, whereas radiographic and bronchoalveolar lavage read-outs (eg, bronchiectasis, increased neutrophil counts) are abnormal, suggesting progression of pulmonary disease despite a normal $\mathrm{FEV}_{1 .}{ }^{109,118,119}$ Clearly, more sensitive outcome parameters are needed to monitor discrete changes in lung disease, especially in early stages of CF. Many groups are investigating the use of multiple breath inert-gas washout to determine the lung clearance index ( $\mathrm{LCl}$ ) for identifying pulmonary abnormalities, such as mucus obstruction. ${ }^{119}$ Other early manifestations of CF airway disease are decreased ASL, abnormal ciliary beating, reduced mucociliary clearance, and impaired bacterial killing, features present even a few hours after birth in neonatal piglets, ferrets and rats. ${ }^{10,11,77,80,107}$

Theoretically, poor transduction and poor clinical outcome in postnatal gene therapy clinical trials for CF could be overcome by gene therapy in the neonatal or fetal period. The advantages of gene transfer in utero are (1) administration before irreversible organ damage, (2) easier access to target cells, (3) longer contact time of the vector, (4) a higher vector to target cell ratio, (5) a less pronounced immune response against transgene and vector with even the possibility of tolerance induction, and (6) the presence of expanding stem and progenitor populations (reviewed in Shangaris and David ${ }^{120}$ ). Initial attempts to transfer the therapeutic gene for CF in mice in utero were done in late 1990s. In a study by Larson and colleagues, gene transfer of AdV-CFTR to CF mouse fetuses restored their severe gastrointestinal phenotype. ${ }^{121}$ Interestingly, CFTR expression was not detected 72 hours after gene transfer suggesting that transient CFTR expression during prenatal development was sufficient to permanently reverse gastrointestinal pathology. This suggests a crucial role for CFTR during prenatal development in mice. In 2008, 2 independent groups failed to replicate these findings, although the original experimental setup was meticulously mimicked, ${ }^{122,123}$ providing no further support for this intriguing hypothesis. ${ }^{122,123}$

CFTR is naturally expressed in ciliated cells of the surface epithelium as well as in the SMG ducts and serous cells of SMG acini. ${ }^{81}$ SMGs are considered a difficult target because of their anatomic location, but in the developing lung, these cell populations might be more easily accessible. ${ }^{124}$ SMG development has been extensively characterized in mice ${ }^{125}$ but also studied in humans by fetal tracheal xenograft models in mice. ${ }^{126}$ In the fully developed SMGs, progenitor cells reside in the SMG ducts, which give rise to cells that form either SMGs or surface epithelium. ${ }^{127}$ These stem cells are likely more accessible during the process of SMG development, which in humans already starts in utero. ${ }^{124,126}$ Evidence for this hypothesis was provided by Keswani et al where rAAV2/2 and rAAV2/8-LacZ targeted fetal SMGs a lot more efficiently than in a postnatal setting and this in a human tracheal xenograft mouse model. ${ }^{124}$ Even the surface epithelium, however, which in theory seems an easy target, is not as easy transduced by gene delivery agents as expected based on its location. ${ }^{72,124}$ One of the major challenges in a postnatal setting is the accumulation of excessive mucus in CF due to recurrent infection and inflammation. As the fetal lungs are typically sterile, this process only starts after birth. ${ }^{10,128}$ Although vector penetration of CF sputum samples has already been assessed for various vector systems postnatally, ${ }^{72}$ it will be of great interest to extend these data to comparative studies between fetal and postnatal, CF and WT. In that regard, the human 
tracheal xenograft mouse model ${ }^{124}$ and human explant lungs ${ }^{129}$ would be appropriate models to compare fetal versus postnatal transduction efficiencies of target cells for CF. Fetal vector delivery furthermore allows efficient and homogenous distribution of injected particles which is likely promoted by their fluid filled nature. This was for example demonstrated in WT pigs and mice after fetal intratracheal delivery of fluospheres or rAAV2/6.2. ${ }^{47,130,131}$ Finally, tolerance to transgenes after fetal or neonatal transduction has been demonstrated for human FIX in mice and dogs. ${ }^{132-134}$ There is however no evidence for tolerance induction against the viral vector itself, probably due to the limited half-life of the viral proteins once injected into the body. ${ }^{132}$ Furthermore, we have learnt from fetal gene therapy studies in mice that vector delivery to an immature immune system allows a single repeated administration due to immunological ignorance against the rAAV capsid, but that later readministrations are hampered by anticapsid neutralizing antibodies. ${ }^{135-137}$ Translation to humans however remains to be investigated.

Despite several indications for a fetal gene therapy, CF is not associated with serious morbidity or mortality in utero, one of the criteria stated by the National Institutes for Health Recombinant DNA Advisory Committee for considering a fetal intervention. ${ }^{138}$ Furthermore, the benefits of the intervention must be weighed against the possible risk for complications, which could range from prelabour rupture of the membranes, vector spread to germline cells or maternal circulation or developmental aberrations for the fetus. ${ }^{139,140}$ Based on current progress in preclinical fetal gene therapy for $\mathrm{CF}$, a neonatal intervention would currently be most realistic for clinical translation. However, if more substantial evidence becomes available on the clear benefits of fetal versus postnatal gene therapy in relevant animal and human airway models, these findings could provide a basis for translating fetal gene therapy to the clinics in the future.

\section{6 | ROADMAP TO SUCCESSFUL GENE THERAPY FOR CF AIRWAY DISEASE}

The complexity of the lung, the need for more efficient vector systems, the tightly controlled CFTR expression and activity, and until recently the absence of animal models developing human-like CF airway disease represent the main barriers to clinical benefit for gene therapy. Many of these obstacles have been addressed in the numerous animal and cell models present to date and are by now better understood. In Figure 1, a schematic overview is given of the contribution of each model in predicting the expected benefit in CF patients. Mouse models are instrumental to study proof-of-principle efficacy by assessing CFTR expression at the transcript or protein level and CFTR function using NPD. Additionally, mechanistic processes can be unraveled relating to vector-mediated gene delivery in a live host, such as immune responses to vector and transgene. Nevertheless, mouse models do not always predict human responses as exemplified by the unexpected cytotoxic T-cell responses to the rAAV capsid in hemophilia B trials which limited the expression of the therapeutic protein. ${ }^{141}$ The larger CF animal models that develop spontaneous lung disease have shown their first application for neonatal gene therapy, where early parameters of CF lung disease (reduced ASL pH and bacterial killing) were corrected by rAAV or LV. ${ }^{55,106}$ Follow-up studies will likely focus on preventing irreversible lung damage by studying the effect of gene therapy on mucociliary clearance, mucus viscosity, mucus plugging, and lung function. These models will furthermore allow correlating clinical lung disease improvements to the level of CFTR rescue and the cell types corrected in the surface epithelium and/or SMGs. Finally, researchers will need to study the optimal time for gene therapy initiation (fetal, neonatal, adult) to achieve efficient airway transduction allowing prevention of irreversible lung disease.

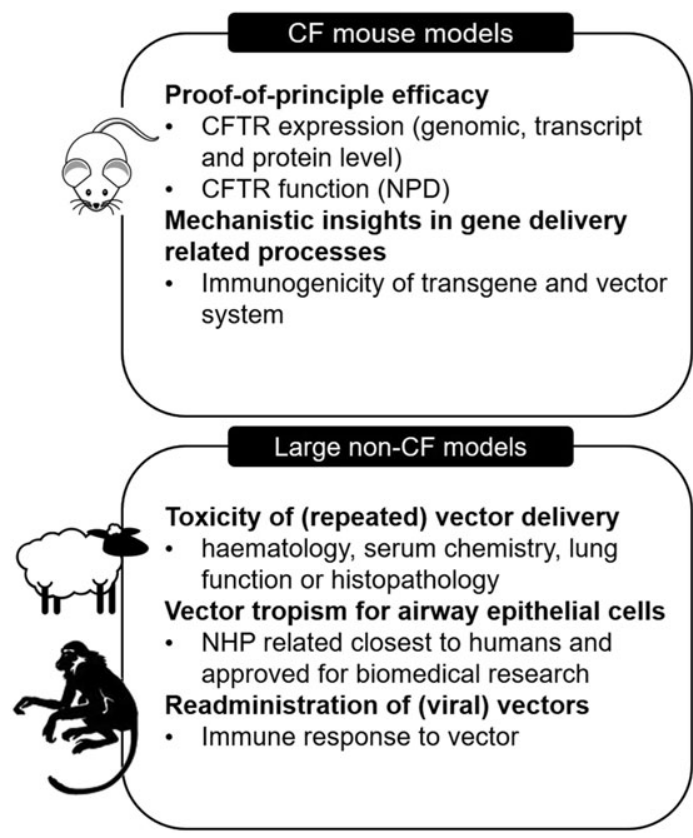

CF models with lung pathology

Prevention or interruption of progressing lung disease

- Early (ASL, MCC, bacterial killing)

- Progressive (lung function, mucus plugging, lung remodelling)

Optimal time point for vector delivery

- Fetal, neontal, adult

Correlation of target cells with CFTR activity and lung disease read-outs
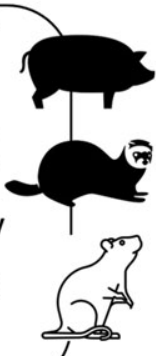

Human airway epithelia

Human tracheal xenograft mouse models and human lung explants

- Transduction of target cells for $\mathrm{CF}$ (surface epithelium and SMGs)

- Fetal, neonatal, adult

Mucus penetration of vector system

- sputum, primary airway cultures Correlation of target cells with CFTR activity

FIGURE 1 Overview of the benefits of different cell and animal models used in gene therapy research for cystic fibrosis (CF). Abbreviations: CFTR: Cystic fibrosis transmembrane conductance regulator, NPD: Nasal potential difference, ASL: Airway surface liquid, MCC: Mucociliary clearance, NHP: Non-human primates, SMGs: Submucosal glands 
Apart from studying CF read-outs, large animal species such as sheep and non-human primates (NHP) have shown their application in vector toxicity, biodistribution, and tropism determination as one of the final steps to clinical translation due to similar lung size and structure as humans (reviewed in Alton et $\mathrm{al}^{29}$ and Flotte et $\mathrm{al}^{142}$ ). For example, sheep have been used to assess acute and chronic vector toxicity to repeated liposome delivery of hCFTR. Regarding NHP, chimpanzees are the closest genetic relatives to humans (reviewed in Flotte et $\mathrm{al}^{142}$ ). The proposed indication for this species is to determine rAAV tropism and capsid immunogenicity, which influence transduction efficiency and longevity of gene expression. ${ }^{142}$ However, they are a protected species and no longer approved for invasive research in many countries. ${ }^{143}$ The rhesus macaque and marmoset have been used to assess safety and toxicity of vector delivery as well as molecular end-points of CFTR expression. ${ }^{144,145}$ Human bronchial epithelial (HBE) cells from lung explants have been the golden standard for CF drug development. ${ }^{146}$ Also, for clinical gene therapy development, HBEs are of value as they present the model most closely mimicking the human airways. The development of human tracheal xenograft mouse models ${ }^{125}$ and human explant lungs ${ }^{129}$ will be invaluable to gather further evidence on a solid comparison of fetal versus postnatal transduction efficiencies of target cells for CF. This will be a starting point to further unravel additional benefits of fetal gene therapy on the longevity of expression, possibility to readminister the vector, and extent to which CF lung disease can be prevented.
In conclusion, the wide array of cell and animal models presenting specific aspects of CF lung disease will contribute to unraveling key questions on the development of an optimal gene therapy protocol for CF. Figure 2 illustrates the proposed roadmap from preclinical to clinical gene therapy for CF. Progressing beyond molecular and electrophysiological end-points will likely increase the success of providing CF patients with a gene therapy treatment that can substantially improve their quality of life by preventing irreversible lung damage.

A first step in the development of a gene therapy for CF is the design of a viral or non-viral vector capable of restoring CFTR expression and function in vitro. Proof-of-principle studies in mice then allow identifying if the vector formulation allows targeting the airways in a live host. This gives a first idea on vector tropism, transduction efficiency at different doses, and longevity of gene expression. Of importance is to confirm as soon as possible in human primary airway cultures the ability of the vector to restore CFTR expression and function. As transduction efficiencies can differ between the fetal and adult period, ${ }^{147}$ human tissues should be collected from the desired period for vector testing. If vectors test negative in this step, improved vector design is necessary. Next, CF animal models that develop spontaneous human-like CF lung disease allow assessing if the vector can restore or even prevent the development of early and progressive lung disease features. Only at this point will it be possible to correlate the level of CFTR expression and function with a clinically meaningful benefit. Also, the time point of vector delivery (fetal, neonatal, adult) can be

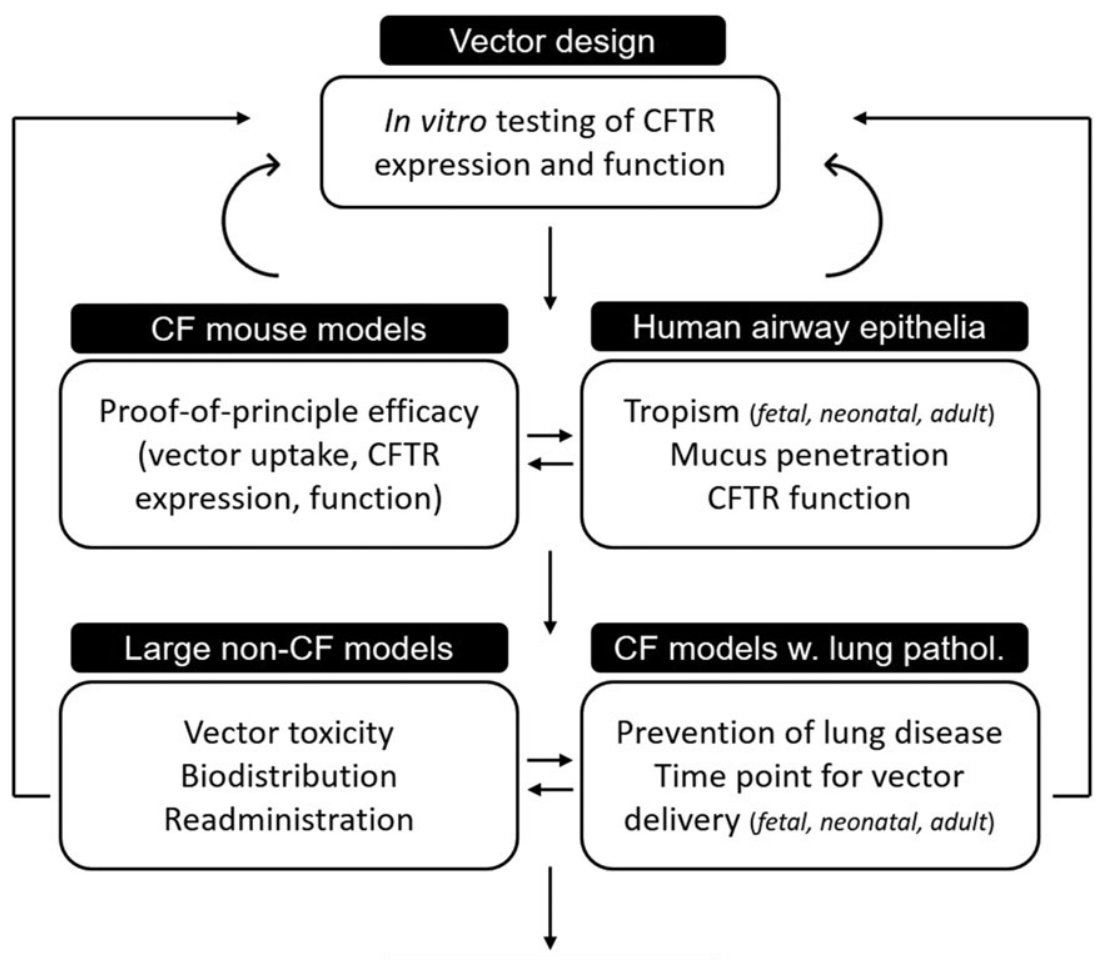

CF patients

Clinical development Safety and efficacy

FIGURE 2 Proposed roadmap for an early gene therapy for cystic fibrosis airway disease 
fine-tuned and correlated with the status of lung disease severity. Finally, large animal models closely related to humans regarding lung anatomy, physiology, and cell composition allow assessing if the vector is well tolerated even after repeated administrations, before progressing into early clinical development.

\section{ACKNOWLEDGEMENTS}

We would like to thank Kris De Boeck, Hugo de Jonge, and Zeger Debyser for their constructive input in writing this review. M.S.C. is a postdoctoral fellow supported by the "Fund Alphonse and Jean Forton", King Baudouin Foundation, Belgium [3M140231].

\section{DISCLOSURE CONFLICT OF INTEREST}

No conflicts of interest.

\section{ORCID}

Marianne S. Carlon (10 http://orcid.org/0000-0002-8263-0350

\section{REFERENCES}

1. Maguire AM, High KA, Auricchio A, et al. Age-dependent effects of RPE65 gene therapy for Leber's congenital amaurosis: a phase 1 dose-escalation trial. Lancet. 2009;374:1597-1605.

2. Gaudet D, Stroes ES, Méthot J, et al. Long-Term Retrospective Analysis of Gene Therapy with Alipogene Tiparvovec and Its Effect on Lipoprotein Lipase Deficiency-Induced Pancreatitis. Hum Gene Ther. 2016;27:916-925.

3. Gaspar HB, Cooray S, Gilmour KC, et al. Hematopoietic Stem Cell Gene Therapy for Adenosine Deaminase-Deficient Severe Combined Immunodeficiency Leads to Long-Term Immunological Recovery and Metabolic Correction. Sci Transl Med. 2011;3:97ra80-97ra80.

4. Hacein-Bey-Abina S, Pai S-Y, Gaspar HB, et al. A Modified $\gamma$-Retrovirus Vector for X-Linked Severe Combined Immunodeficiency. N Engl J Med. 2014;371:1407-1417.

5. Nathwani AC, Reiss UM, Tuddenham EGD, et al. Long-Term Safety and Efficacy of Factor IX Gene Therapy in Hemophilia B. N Engl J Med. 2014;371:1994-2004.

6. GLOBE NEWSWIRE. AveXis Receives U.S. FDA Breakthrough Therapy Designation for AVXS-101 Gene Replacement Therapy for Spinal Muscular Atrophy Type 1. Press Release (2016).

7. Zolin A van Rens J et al., M. E. F. European Cystic Fibrosis Patient Registry (ECFPR) Annual Report 2014. (2016). Available at: https://www. ecfs.eu/projects/ecfs-patient-registry/annual-reports.

8. Guggino WB, Stanton BA. New insights into cystic fibrosis: molecular switches that regulate CFTR. Nat Rev Mol Cell Biol. 2006;7:426-436.

9. Borowitz D. CFTR, bicarbonate, and the pathophysiology of cystic fibrosis. Pediatr Pulmonol. 2015;50(Suppl 4):S24-S30.

10. Pezzulo AA, Tang XX, Hoegger MJ, et al. Reduced airway surface $\mathrm{pH}$ impairs bacterial killing in the porcine cystic fibrosis lung. Nature. 2012;487:109-113.

11. Keiser NW, Birket SE, Evans IA, et al. Defective innate immunity and hyperinflammation in newborn cystic fibrosis transmembrane conductance regulator-knockout ferret lungs. Am J Respir Cell Mol Biol. 2015;52:683-694.

12. Riordan JR, Rommens JM, Kerem B, et al. Identification of the cystic fibrosis gene: cloning and characterization of complementary DNA. Science. 1989;245(80):1066-1073.

13. Rommens J, lannuzzi M, Kerem B, et al. Identification of the cystic fibrosis gene: chromosome walking and jumping. Science. 1989;245(80):1059-1065.
14. Kerem B, Rommens JM, Buchanan JA, et al. Identification of the cystic fibrosis gene: genetic analysis. Science. 1989;245(80):1073-1080.

15. Sondhi D, Stiles KM, De BP, Crystal RG. Genetic Modification of the Lung Directed Toward Treatment of Human Disease. Hum Gene Ther. 2017;28:3-84.

16. Alton EWFW, Boyd AC, Davies JC, et al. Genetic medicines for CF: Hype versus reality. Pediatr Pulmonol. 2016;51:S5-S17.

17. Alton EW, Armstrong DK, Ashby D, et al. Repeated nebulisation of non-viral CFTR gene therapy in patients with cystic fibrosis: a randomised, double-blind, placebo-controlled, phase $2 \mathrm{~b}$ trial. Lancet Respir Med. 2015;3:684-691.

18. Doudna, J. A. \& Charpentier, E. Genome editing. The new frontier of genome engineering with CRISPR-Cas9. Science 346, 1258096-11258096-9 (2014).

19. Cuculis L, Schroeder CM. A Single-Molecule View of Genome Editing Proteins: Biophysical Mechanisms for TALEs and CRISPR/Cas9. Annu Rev Chem Biomol Eng. 2017;8:577-597.

20. Schwank G, Koo BK, Sasselli V, et al. Functional repair of CFTR by CRISPR/Cas9 in intestinal stem cell organoids of cystic fibrosis patients. Cell Stem Cell. 2013;13:653-658.

21. Schaefer KA, Wu WH, Colgan DF, Tsang SH, Bassuk AG, Mahajan VB. Unexpected mutations after CRISPR-Cas9 editing in vivo. Nat Methods. 2017; 14:547-548.

22. Liang $\mathrm{P}, \mathrm{Xu} \mathrm{Y}$, Zhang $\mathrm{X}$, et al. CRISPR/Cas9-mediated gene editing in human tripronuclear zygotes. Protein Cell. 2015;6:363-372.

23. Weiss DJ. Concise review: current status of stem cells and regenerative medicine in lung biology and diseases. Stem Cells. 2014;32:16-25.

24. Ghosh M, Ahmad S, White CW, Reynolds SD. Transplantation of Airway Epithelial Stem/Progenitor Cells: A Future for Cell-Based Therapy. Am J Respir Cell Mol Biol. 2017;56:1-10.

25. Keles E, Song Y, Du D, Dong W-J, Lin Y. Recent progress in nanomaterials for gene delivery applications. Biomater Sci. 2016;4:1291-1309.

26. Yin H, Kanasty RL, Eltoukhy AA, Vegas AJ, Dorkin JR, Anderson DG. Non-viral vectors for gene-based therapy. Nat Rev Genet. 2014;15:541-555.

27. Samulski RJ, Muzyczka N. AAV-Mediated Gene Therapy for Research and Therapeutic Purposes. Annu Rev Virol. 2014;1:427-451.

28. Yin H, Kauffman KJ, Anderson DG. Delivery technologies for genome editing. Nat Rev Drug Discov. 2017. https://doi.org/10.1038/ nrd.2016.280

29. Alton EWFW, Baker A, Baker E, et al. The safety profile of a cationic lipid-mediated cystic fibrosis gene transfer agent following repeated monthly aerosol administration to sheep. Biomaterials. 2013;34:10267-10277.

30. Cheng CJ, Saltzman WM. Enhanced siRNA delivery into cells by exploiting the synergy between targeting ligands and cell-penetrating peptides. Biomaterials. 2011;32:6194-6203.

31. Crystal RG, McElvaney NG, Rosenfeld MA, et al. Administration of an adenovirus containing the human CFTR CDNA to the respiratory tract of individuals with cystic fibrosis. Nat Genet. 1994;8:42-51.

32. Zabner J, Couture LA, Gregory RJ, Graham SM, Smith AE, Welsh MJ. Adenovirus-mediated gene transfer transiently corrects the chloride transport defect in nasal epithelia of patients with cystic fibrosis. Cell. 1993;75:207-216.

33. Zabner J, Ramsey BW, Meeker DP, et al. Repeat administration of an adenovirus vector encoding cystic fibrosis transmembrane conductance regulator to the nasal epithelium of patients with cystic fibrosis. J Clin Invest. 1996;97:1504-1511.

34. Harvey BG, Leopold PL, Hackett NR, et al. Airway epithelial CFTR mRNA expression in cystic fibrosis patients after repetitive administration of a recombinant adenovirus. J Clin Invest. 1999;104:12451255. 
35. Alba R, Bosch A, Chillon M. Gutless adenovirus: last-generation adenovirus for gene therapy. Gene Ther. 2005;12:S18-S27.

36. Cao H, Yang T, Li XF, et al. Readministration of helper-dependent adenoviral vectors to mouse airway mediated via transient immunosuppression. Gene Ther. 2011;18:173-181.

37. Dismuke DJ, Tenenbaum L, Samulski RJ. Biosafety of Recombinant Adeno-associated Virus Vectors. Curr Gene Ther. 2013; doi:CGTEPUB-57247 [pii]

38. Wagner JA, Nepomuceno IB, Messner AH, et al. A phase II, doubleblind, randomized, placebo-controlled clinical trial of tgAAVCF using maxillary sinus delivery in patients with cystic fibrosis with antrostomies. Hum Gene Ther. 2002;13:1349-1359.

39. Wagner JA, Messner AH, Moran ML, et al. Safety and biological efficacy of an adeno-associated virus vector-cystic fibrosis transmembrane regulator (AAV-CFTR) in the cystic fibrosis maxillary sinus. Laryngoscope. 1999;109:266-274.

40. Moss RB, Rodman D, Spencer LT, et al. Repeated adeno-associated virus serotype 2 aerosol-mediated cystic fibrosis transmembrane regulator gene transfer to the lungs of patients with cystic fibrosis: a multicenter, double-blind, placebo-controlled trial. Chest. 2004;125:509-521.

41. Moss RB, Milla C, Colombo J, et al. Repeated aerosolized AAV-CFTR for treatment of cystic fibrosis: a randomized placebo-controlled phase 2B trial. Hum Gene Ther. 2007;18:726-732.

42. Flotte TR, Zeitlin PL, Reynolds TC, et al. Phase I trial of intranasal and endobronchial administration of a recombinant adeno-associated virus serotype 2 (rAAV2)-CFTR vector in adult cystic fibrosis patients: a two-part clinical study. Hum Gene Ther. 2003;14:1079-1088.

43. Pillay S, Meyer NL, Puschnik AS, et al. An essential receptor for adenoassociated virus infection. Nature. 2016;530:108-112.

44. Limberis MP, Vandenberghe LH, Zhang L, Pickles RJ, Wilson JM. Transduction efficiencies of novel AAV vectors in mouse airway epithelium in vivo and human ciliated airway epithelium in vitro. Mol Ther. 2009;17:294-301.

45. Vidovic D, Carlon MS, da Cunha MF, et al. rAAV-CFTRDeltaR Rescues the Cystic Fibrosis Phenotype in Human Intestinal Organoids and Cystic Fibrosis Mice. Am J Respir Crit Care Med. 2016;193:288-298.

46. Vidovic D, Gijsbers R, Quiles Jimenez A, et al. Noninvasive Imaging Reveals Stable Transgene Expression in Mouse Airways After Delivery of a Nonintegrating Recombinant Adeno-Associated Viral Vector. Hum Gene Ther. 2016;27:60-71.

47. Carlon M, Toelen J, Van der Perren A, et al. Efficient gene transfer into the mouse lung by fetal intratracheal injection of rAAV2/6.2. Mol Ther. 2010;18:2130-2138.

48. Yan Z, Sun X, Feng Z, et al. Optimization of Recombinant Adeno-Associated Virus-Mediated Expression for Large Transgenes, Using a Synthetic Promoter and Tandem Array Enhancers. Hum Gene Ther. 2015;26:334-346.

49. Ostedgaard LS, Rokhlina T, Karp PH, et al. A shortened adeno-associated virus expression cassette for CFTR gene transfer to cystic fibrosis airway epithelia. Proc Natl Acad Sci U S A. 2005;102:2952-2957.

50. Ostedgaard LS, Zabner J, Vermeer DW, et al. CFTR with a partially deleted $\mathrm{R}$ domain corrects the cystic fibrosis chloride transport defect in human airway epithelia in vitro and in mouse nasal mucosa in vivo. Proc Natl Acad Sci U S A. 2002;99:3093-3098.

51. Cebotaru L, Woodward O, Cebotaru V, Guggino WB. Transcomplementation by a truncation mutant of cystic fibrosis transmembrane conductance regulator (CFTR) enhances DeltaF508 processing through a biomolecular interaction. J Biol Chem. 2013;288:10505-10512.

52. Cormet-Boyaka E, Jablonsky M, Naren AP, Jackson PL, Muccio DD, Kirk KL. Rescuing cystic fibrosis transmembrane conductance regulator (CFTR)-processing mutants by transcomplementation. Proc Natl Acad Sci U S A. 2004;101:8221-8226.
53. Alton EWFW, Beekman JM, Boyd AC, et al. Preparation for a first-inman lentivirus trial in patients with cystic fibrosis. Thorax. 2016;72:137-147.

54. Cmielewski P, Donnelley M, Parsons DW. Long-term therapeutic and reporter gene expression in lentiviral vector treated cystic fibrosis mice. J Gene Med. 2014;16:291-299.

55. Cooney AL, Abou Alaiwa MH, Shah VS, et al. Lentiviral-mediated phenotypic correction of cystic fibrosis pigs. JCI Insight. 2016;1:e88730

56. Mitomo K, Griesenbach U, Inoue M, et al. Toward gene therapy for cystic fibrosis using a lentivirus pseudotyped with Sendai virus envelopes. Mol Ther. 2010;18:1173-1182.

57. Griesenbach U, Inoue M, Meng C, et al. Assessment of F/HNpseudotyped lentivirus as a clinically relevant vector for lung gene therapy. Am J Respir Crit Care Med. 2012;186:846-856.

58. Rogers CS, Hao Y, Rokhlina T, et al. Production of CFTR-null and CFTR-DeltaF508 heterozygous pigs by adeno-associated virus-mediated gene targeting and somatic cell nuclear transfer. J Clin Invest. 2008;118:1571-1577.

59. Rogers CS, Stoltz DA, Meyerholz DK, et al. Disruption of the CFTR gene produces a model of cystic fibrosis in newborn pigs. Science. 2008;321(80):1837-1841.

60. Wilke M, Buijs-Offerman RM, Aarbiou J, et al. Mouse models of cystic fibrosis: Phenotypic analysis and research applications. J Cyst Fibros. 2011;10:

61. Conese M, Ascenzioni F, Boyd AC, et al. Gene and cell therapy for cystic fibrosis: from bench to bedside. J Cyst Fibros. 2011;10(Suppl 2): S114-S128.

62. Grubb BR, Boucher RC. Pathophysiology of gene-targeted mouse models for cystic fibrosis. Physiol Rev. 1999;79:S193-S214.

63. Griesenbach U, Smith SN, Farley R, Singh C, Alton EW. Validation of nasal potential difference measurements in gut-corrected CF knockout mice. Am J Respir Cell Mol Biol. 2008;39:490-496.

64. Saussereau EL, Roussel D, Diallo S, Debarbieux L, Edelman A, SermetGaudelus I. Characterization of nasal potential difference in cftr knockout and F508del-CFTR mice. PLoS One. 2013;8:e57317

65. Limberis M, Anson DS, Fuller M, Parsons DW. Recovery of airway cystic fibrosis transmembrane conductance regulator function in mice with cystic fibrosis after single-dose lentivirus-mediated gene transfer. Hum Gene Ther. 2002;13:1961-1970.

66. McNeer NA, Anandalingam K, Fields RJ, et al. Nanoparticles that deliver triplex-forming peptide nucleic acid molecules correct F508del CFTR in airway epithelium. Nat Commun. 2015;6:6952

67. Mingozzi F, High KA. Therapeutic in vivo gene transfer for genetic disease using AAV: progress and challenges. Nat Rev Genet. 2011;12:341-355.

68. Mall M, Grubb BR, Harkema JR, O'Neal WK, Boucher RC. Increased airway epithelial $\mathrm{Na}+$ absorption produces cystic fibrosis-like lung disease in mice. Nat Med. 2004;10:487-493.

69. Welsh MJ, Rogers CS, Stoltz DA, Meyerholz DK, Prather RS. Development of a porcine model of cystic fibrosis. Trans Am Clin Climatol Assoc. 2009;120:149-162.

70. Sun X, Sui H, Fisher JT, et al. Disease phenotype of a ferret CFTRknockout model of cystic fibrosis. J Clin Invest. 2010;120:3149-3160.

71. Crosby LM, Waters CM. Epithelial repair mechanisms in the lung. AJP Lung Cell Mol Physiol. 2010;298:L715-L731.

72. Duncan GA, Jung J, Hanes J, Suk JS. The Mucus Barrier to Inhaled Gene Therapy. Mol Ther. 2016;24:2043-2053.

73. Johnson JS, Gentzsch M, Zhang L, et al. AAV exploits subcellular stress associated with inflammation, endoplasmic reticulum expansion, and misfolded proteins in models of cystic fibrosis. PLoS Pathog. 2011;7:

74. Monahan PE, Lothrop CD, Sun J, et al. Proteasome inhibitors enhance gene delivery by AAV virus vectors expressing large genomes in hemophilia mouse and dog models: a strategy for broad clinical application. Mol Ther. 2010;18:1907-1916. 
75. Yan Z, Sun X, Evans IA, et al. Postentry processing of recombinant adeno-associated virus type 1 and transduction of the ferret lung are altered by a factor in airway secretions. Hum Gene Ther. 2013;24:786-796.

76. Mitchell AM, Samulski RJ. Mechanistic insights into the enhancement of adeno-associated virus transduction by proteasome inhibitors. $J$ Virol. 2013;87:13035-13041.

77. Tuggle KL, Birket SE, Cui X, et al. Characterization of defects in ion transport and tissue development in cystic fibrosis transmembrane conductance regulator (CFTR)-knockout rats. PLoS One. 2014;9: e91253

78. Klymiuk N, Mundhenk L, Kraehe K, et al. Sequential targeting of CFTR by BAC vectors generates a novel pig model of cystic fibrosis. J Mol Med. 2012;90:597-608.

79. Li X, Tang XX, Vargas Buonfiglio LG, et al. Electrolyte transport properties in distal small airways from cystic fibrosis pigs with implications for host defense. Am J Physiol Lung Cell Mol Physiol. 2016;310:L670L679.

80. Hoegger MJ, Fischer AJ, McMenimen JD, et al. Impaired mucus detachment disrupts mucociliary transport in a piglet model of cystic fibrosis. Science. 2014;345(80):818-822.

81. Engelhardt JF, Yankaskas JR, Ernst SA, et al. Submucosal glands are the predominant site of CFTR expression in the human bronchus. Nat Genet. 1992;2:240-248.

82. Joo NS, Cho HJ, Khansaheb M, Wine JJ. Hyposecretion of fluid from tracheal submucosal glands of CFTR-deficient pigs. J Clin Invest. 2010;120:3161-3166.

83. Steines B, Dickey DD, Bergen J, et al. CFTR gene transfer with AAV improves early cystic fibrosis pig phenotypes. JCI Insight. 2016;1: e88728

84. Birket SE, Chu KK, Liu L, et al. A functional anatomic defect of the cystic fibrosis airway. Am J Respir Crit Care Med. 2014;190:421-432.

85. Stoltz DA, Meyerholz DK, Pezzulo AA, et al. Cystic fibrosis pigs develop lung disease and exhibit defective bacterial eradication at birth. Sci Transl Med. 2010;2:29ra31

86. Sly PD, Gangell CL, Chen L, et al. Risk factors for bronchiectasis in children with cystic fibrosis. N Engl J Med. 2013;368:1963-1970.

87. Boon M, Verleden SE, Bosch B, et al. Morphometric analysis of explant lungs in cystic fibrosis. Am J Respir Crit Care Med. 2016;193:516-526.

88. Vande Velde G, Poelmans J, De Langhe E, et al. Longitudinal micro-CT provides biomarkers of lung disease and therapy in preclinical models, thereby revealing compensatory changes in lung volume. Dis Model Mech. 2016;9:91-98.

89. Adam RJ, Michalski AS, Bauer C, et al. Air trapping and airflow obstruction in newborn cystic fibrosis piglets. Am J Respir Crit Care Med. 2013;188:1434-1441.

90. Darrah RJ, Mitchell AL, Campanaro CK, et al. Early pulmonary disease manifestations in cystic fibrosis mice. J Cyst Fibros. 2016;15:736-744.

91. Vanoirbeek J. a J., Rinaldi, M., De Vooght, V., et al. Noninvasive and invasive pulmonary function in mouse models of obstructive and restrictive respiratory diseases. Am J Respir Cell Mol Biol. 2010;42:96-104.

92. Biffi A, Montini E, Lorioli L, et al. Lentiviral Hematopoietic Stem Cell Gene Therapy Benefits Metachromatic Leukodystrophy. Science. 2013;341, 1233158-1233158(80):

93. Farrell PM, White TB, Howenstine MS, et al. Diagnosis of Cystic Fibrosis in Screened Populations. J Pediatr. 2017;181:S33-S44.

94. Dijk FN, Fitzgerald DA. The impact of newborn screening and earlier intervention on the clinical course of cystic fibrosis. Paediatr Respir Rev. 2012;13:220-225.

95. Castellani C, Massie J, Sontag M, Southern KW. Newborn screening for cystic fibrosis. Lancet Respir Med. 2016;4:653-661.
96. Owens CM, Aurora P, Stanojevic S, et al. Lung Clearance Index and HRCT are complementary markers of lung abnormalities in young children with CF. Thorax. 2011;66:481-488.

97. Shangaris, P. \& David, A. L. Perinatal gene therapy. in Fetal Stem Cells in Regenerative Medicine - Principles and Translational Strategies (eds. Fauza, D. O. \& Bani, M.) 1-441 (Humana Press, 2016). doi:https:// doi.org/10.1007/978-1-4939-3483-6

98. Larson JE, Morrow SL, Happel L, Sharp JF, Cohen JC. Reversal of cystic fibrosis phenotype in mice by gene therapy in utero. Lancet. 1997;349:619-620.

99. Davies LA, Varathalingam A, Painter $\mathrm{H}$, et al. Adenovirus-mediated in utero expression of CFTR does not improve survival of CFTR knockout mice. Mol Ther. 2008;16:812-818.

100. Buckley SM, Waddington SN, Jezzard S, et al. Intra-amniotic delivery of CFTR-expressing adenovirus does not reverse cystic fibrosis phenotype in inbred CFTR-knockout mice. Mol Ther. 2008;16:819-824.

101. Keswani SG, Balaji S, Le L, et al. Pseudotyped AAV vector-mediated gene transfer in a human fetal trachea xenograft model: Implications for in Utero gene therapy for cystic fibrosis. PLoS One. 2012;7:

102. May A, Tucker A. Understanding the development of the respiratory glands. Dev Dyn. 2015;244:525-539.

103. Keswani SG, Le LD, Morris LM, et al. Submucosal gland development in the human fetal trachea xenograft model: implications for fetal gene therapy. J Pediatr Surg. 2011;46:33-38.

104. Hegab AE, Nickerson DW, Ha VL, Darmawan DO, Gomperts BN. Repair and regeneration of tracheal surface epithelium and submucosal glands in a mouse model of hypoxic-ischemic injury. Respirology. 2012;17:1101-1113.

105. Sun X, Olivier AK, Liang B, et al. Lung phenotype of juvenile and adult cystic fibrosis transmembrane conductance regulator-knockout ferrets. Am J Respir Cell Mol Biol. 2014;50:502-512.

106. Del Moral PM, Warburton D. Explant culture of mouse embryonic whole lung, isolated epithelium, or mesenchyme under chemically defined conditions as a system to evaluate the molecular mechanism of branching morphogenesis and cellular differentiation. Methods Mol Biol. 2010;633:71-79.

107. Carlon MS, Engels AC, Bosch B, et al. A novel translational model for fetoscopic intratracheal delivery of nanoparticles in piglets. Prenat Diagn. 2016;36:926-934.

108. Carlon MS, Toelen J, da Cunha MM, et al. A novel surgical approach for intratracheal administration of bioactive agents in a fetal mouse model. J Vis Exp. 2012;(68). pii:, https://doi.org/10.3791/4219):

109. Waddington SN, Buckley SM, Nivsarkar M, et al. In utero gene transfer of human factor IX to fetal mice can induce postnatal tolerance of the exogenous clotting factor. Blood. 2003;101:1359-1366.

110. Waddington SN, Nivsarkar MS, Mistry AR, et al. Permanent phenotypic correction of hemophilia $B$ in immunocompetent mice by prenatal gene therapy. Blood. 2004;104:2714-2721.

111. Zhang J, Xu L, Haskins ME, Parker Ponder K. Neonatal gene transfer with a retroviral vector results in tolerance to human factor IX in mice and dogs. Blood. 2004;103:143-151.

112. Carlon MS, Vidović D, Dooley J, et al. Immunological Ignorance Allows Long-Term Gene Expression After Perinatal Recombinant AdenoAssociated Virus-Mediated Gene Transfer to Murine Airways. Hum Gene Ther. 2014;12:1-12.

113. Hu C, Cela RG, Suzuki M, Lee B, Lipshutz GS. Neonatal helper-dependent adenoviral vector gene therapy mediates correction of hemophilia A and tolerance to human factor VIII. Proc Natl Acad Sci U S A. 2011;108:2082-2087.

114. Sabatino DE, Mackenzie TC, Peranteau W, et al. Persistent expression of hF.IX After tolerance induction by in utero or neonatal administration of AAV-1-F.IX in hemophilia B mice. Mol Ther. 2007;15:16771685. 
115. Committee., U. S. N. I. of H. R. D. N. A. A. Prenatal gene tranfer: scientific, medical, and ethical issues: a report of the Recombinant DNA Advisory Committee. Hum Gene Ther. 2000;11:1211-1229.

116. Toelen J, Carlon M, Claus F, et al. The fetal respiratory system as target for antenatal therapy. Facts, views Vis ObGyn. 2011;3:22-35.

117. Deprest J, Jani J, Lewi L, et al. Fetoscopic surgery: Encouraged by clinical experience and boosted by instrument innovation. Semin Fetal Neonatal Med. 2006;11:398-412.

118. Manno CS, Pierce GF, Arruda VR, et al. Successful transduction of liver in hemophilia by AAV-Factor IX and limitations imposed by the host immune response. Nat Med. 2006;12:342-347.

119. Flotte TR, Fischer AC, Goetzmann J, et al. Dual reporter comparative indexing of rAAV pseudotyped vectors in chimpanzee airway. Mol Ther. 2010;18:594-600.

120. http://www.sciencemag.org/news/2015/11/nih-end-all-supportchimpanzee-research. NIH to end all support for chimpanzee research. (2015).

121. Fischer AC, Smith $\mathrm{Cl}$, Cebotaru L, et al. Expression of a truncated cystic fibrosis transmembrane conductance regulator with an AAV5pseudotyped vector in primates. Mol Ther. 2007;15:756-763.

122. Farrow N, Miller D, Cmielewski P, Donnelley M, Bright R, Parsons DW. Airway gene transfer in a non-human primate: lentiviral gene expression in marmoset lungs. Sci Rep. 2013;3:1287

123. Awatade NT, Uliyakina I, Farinha CM, et al. Measurements of Functional Responses in Human Primary Lung Cells as a Basis for Personalized Therapy for Cystic Fibrosis. EBioMedicine. 2015;2:147153.

124. Fisher JT, Tyler SR, Zhang Y, et al. Bioelectric characterization of epithelia from neonatal CFTR knockout ferrets. Am J Respir Cell Mol Biol. 2013;49:837-844.

125. Chen JH, Stoltz DA, Karp PH, et al. Loss of anion transport without increased sodium absorption characterizes newborn porcine cystic fibrosis airway epithelia. Cell. 2010;143:911-923.

126. Li X, Comellas AP, Karp PH, et al. CFTR is required for maximal transepithelial liquid transport in pig alveolar epithelia. Am J Physiol Lung Cell Mol Physiol. 2012;303:L152-L160.

127. Shah VS, Meyerholz DK, Tang XX, et al. Airway acidification initiates host defense abnormalities in cystic fibrosis mice. Science. 2016;351(80):503-507.

128. Birket SE, Tuggle KL, Oden AM, et al. The Mucus Transport Defect in the CF rat airway is normalized by addition of bicarbonate. 30th Annual North Am Cystic Fibrosis Conf. 2016;45:S81-S114.

129. Griesenbach U, Boyd AC. Pre-clinical and clinical endpoint assays for cystic fibrosis gene therapy. J Cyst Fibros. 2005;4:89-100.

130. Martens CJ, Inglis SK, Valentine VG, Garrison J, Conner GE, Ballard ST. Mucous solids and liquid secretion by airways: studies with normal pig, cystic fibrosis human, and non-cystic fibrosis human bronchi. Am J Physiol Lung Cell Mol Physiol. 2011;301:L236-L246.

131. Grubb BR, Jones JH, Boucher RC. Mucociliary transport determined by in vivo microdialysis in the airways of normal and CF mice. Am J Physiol Lung Cell Mol Physiol. 2004;286:L588-L595.

132. Hoegger MJ, Awadalla M, Namati E, et al. Assessing mucociliary transport of single particles in vivo shows variable speed and preference for the ventral trachea in newborn pigs. Proc Natl Acad Sci U S A. 2014;111:2355-2360.
133. lanowski JP, Choi JY, Wine JJ, Hanrahan JW. Mucus secretion by single tracheal submucosal glands from normal and cystic fibrosis transmembrane conductance regulator knockout mice. J Physiol. 2007;580:301-314.

134. Su X, Looney MR, Su H, Lee JW, Song Y, Matthay MA. Role of CFTR expressed by neutrophils in modulating acute lung inflammation and injury in mice. Inflamm Res. 2011;60:619-632.

135. Mueller C, Braag SA, Keeler A, Hodges C, Drumm M, Flotte TR. Lack of cystic fibrosis transmembrane conductance regulator in CD3+ lymphocytes leads to aberrant cytokine secretion and hyperinflammatory adaptive immune responses. Am J Respir Cell Mol Biol. 2011;44:922929

136. Stoltz DA, Rokhlina T, Ernst SE, et al. Intestinal CFTR expression alleviates meconium ileus in cystic fibrosis pigs. J Clin Invest. 2013;123:2685-2693.

137. Wallace HL, Southern KW, Connell MG, Wray S, Burdyga T. Abnormal tracheal smooth muscle function in the CF mouse. Physiol Rep. 2013;1:1-11.

138. Chang EH, Pezzulo AA, Meyerholz DK, et al. Sinus hypoplasia precedes sinus infection in a porcine model of cystic fibrosis. Laryngoscope. 2012;122:1898-1905.

139. Diwakar A, Adam RJ, Michalski AS, et al. Sonographic evidence of abnormal tracheal cartilage ring structure in cystic fibrosis. Laryngoscope. 2015;125:2398-2404.

140. Ostedgaard LS, Meyerholz DK, Chen J-H, et al. The F508 Mutation Causes CFTR Misprocessing and Cystic Fibrosis-Like Disease in Pigs. Sci Transl Med. 2011;3:74ra24-74ra24.

141. Lavelle GM, White MM, Browne N, McElvaney NG, Reeves EP. Animal Models of Cystic Fibrosis Pathology: Phenotypic Parallels and Divergences. Biomed Res Int. 2016;2016:

142. Scholte BJ, Davidson DJ, Wilke M, De Jonge HR. Animal models of cystic fibrosis. J Cyst Fibros. 2004;3(Suppl 2):183-190.

143. Rock JR, O'Neal WK, Gabriel SE, et al. Transmembrane protein 16A (TMEM16A) is a Ca2+-regulated $\mathrm{Cl}$ - secretory channel in mouse airways. J Biol Chem. 2009;284:14875-14880.

144. Lee RJ, Foskett JK. Why mouse airway submucosal gland serous cells do not secrete fluid in response to CAMP stimulation. J Biol Chem. 2012;287:38316-38326.

145. Larson JE, Delcarpio JB, Farberman MM, Morrow SL, Cohen JC. CFTR modulates lung secretory cell proliferation and differentiation. Am J Physiol Lung Cell Mol Physiol. 2000;279:L333-L341.

146. Broackes-Carter FC, Mouchel N, Gill D, Hyde S, Bassett J, Harris A. Temporal regulation of CFTR expression during ovine lung development: implications for CF gene therapy. Hum Mol Genet. 2002;11:125-131.

147. Buckley SMK, Howe SJ, Sheard V, et al. Lentiviral transduction of the murine lung provides efficient pseudotype and developmental stagedependent cell-specific transgene expression. Gene Ther. 2008;15:1167-1175.

How to cite this article: Carlon MS, Vidović D, Birket S. Roadmap for an early gene therapy for cystic fibrosis airway disease. Prenatal Diagnosis. 2017;1-10. https://doi.org/ 10.1002/pd.5164 